\title{
Borderline Personality in Serious Delinquents
}

\author{
Michael McManus, Arthur Brickman, Norman E. Alessi, and \\ Wm. Lexington Grapentine
}

\begin{abstract}
Seventy-one seriously delinquent adolescents ( $40 \mathrm{male}, 31$ female) were evaluated by two of the authors (an interviewer and an observer) using the Social Adaptation and Interpersonal Relations sections of the DIB (Diagnostic Interview for Borderlines) in combination with the SADS (Schedule for Affective Disorders and Schizophrenia). DIB scores and DSM-III diagnoses were assigned to each subject by the consensus of the two evaluators. Twenty-six subjects received a primary DSM-III diagnosis of borderline personality disorder. Nineteen (73\%) of these subjects were also identified as borderline by the DIB. The DIB was generally successful in differentiating the DSMIII borderlines from subjects with other DSM-III diagnoses on DIB total, subscale and statement scores. Subjects with a DSM-III diagnosis of major affective disorder were frequently inappropriately categorized as borderline by the DIB, however, reasons for the difficulty of the DIB in distinguishing delinquent adolescents with borderline personalities from those with major affective disorder are discussed, comparisons with adult studies using the DIB are made and directions for future research are indicated.
\end{abstract}

7 HERE has been a great deal of interest in borderline phenomena in adolescence. ${ }^{12,13,17}$ To date, studies have focused primarily on the identification of psychodynamic factors important in the genesis of these conditions and their treatment with psychotherapy. ${ }^{14,18,19}$ Because of the limitations of this investigatory approach, basic questions about borderline phenomena in adolescence remain unanswered. These questions include: (1) Can adolescent borderlines be reliably diagnosed using methods and diagnostic criteria developed for establishing the diagnosis in adults?; and (2) What relationships exist between the borderline diagnosis in adolescence and major affective disorders, schizophrenia and other character disorders?

Previous studies of delinquent adolescents have concluded that borderline conditions make a significant contribution to the psychopathology seen in this group..$^{15,24}$ Offer, Marohn and Ostrow ${ }^{15}$ in their study of psychiatrically hospitalized delinquents described four personality types which defined their sample. Two of these personality types were borderline, the empty borderline and the depressed borderline. In another study also designed to define personality types, Taylor-Gibbs ${ }^{24}$ found borderline personality to be a frequent type in her sample of delinquent girls. Other current studies of delinquent populations ${ }^{2,7,10,11}$ have found that both major affective disorder and schizophrenia or "schizophrenic spectrum" symptoms occur with high frequency in these adolescents. These studies suggest that in addition to borderline conditions, delinquent adolescents exhibit a wide range of psychopathology.

Studies of borderline phenomena in adults have been more systematic than those in adolescents. ${ }^{3,6,16}$ The Diagnostic Interview for Borderlines (DIB) ${ }^{9}$ is currently in

From the Children's Psychiatric Hospital, University of Michigan Hospitals, Ann Arbor, Michigan. Address reprint requests to Michael McManus, MD, Children's Psychiatric Hospital, University of Michigan Hospitals, 1275 N. Hospital Drive, Box 52, Ann Arbor, MI 48109.

(c) 1984 by Grune \& Stratton, Inc. 0010-440X/84/2504-0007\$01.00/0 
wide use for the diagnosis of borderline conditions in adults. A semistructured interview, the DIB directs questions at five areas (social adaptation, impulsivity, affect, psychosis and interpersonal relations) in which borderline symptoms are likely to be found. In the studies of Gunderson ${ }^{4}$ and in replication studies by Soloff ${ }^{20.21}$ the DIB has been shown to adequately differentiate borderline subjects from those with schizophrenia, major affective disorders and "neurotic" depression. In a study of the intersection of DIB and DSM-III definitions of the borderline diagnosis, Kroll et al. ${ }^{8}$ found that $80 \%$ of the subjects identified by the DSM-III as borderline were also identified as borderline by the DIB. Together these studies indicate that while further research is needed before the borderline diagnosis is fully validated, the DIB has proven to be a useful and reliable research instrument.

The current study, which is part of a larger study of psychopathology in seriously delinquent adolescents, was designed to generate pilot data regarding the diagnosis of borderline conditions in adolescents. Structured interview techniques are utilized and the relationship between DIB defined and DMS-III defined borderline conditions is examined.

\section{MATERIALS AND METHODS}

Subjects in this study were delinquent adolescents housed in the training school system in the State of Michigan. Males were chosen from two programs designed for the serious offender. The total population of these programs at the time of the study was 120 . Female subjects were chosen from the State's only residential facility for delinquent girls, with a total population of 60 . Subjects were selected based on a set of criteria designed to identify the most serious and recidivistic juvenile offenders. These criteria included: (1) commission of violent felonies (murder, rape, armed robbery, felonious assault. arson or kidnapping), (2) commission of multiple (three or more) non-violent felonies, (3) muitiple placements in the training school system, and (4) assaultive in-program behavior which required that the victim receive medical attention. Subjects were considered appropriate for evaluation if they met at least two of these criteria. Felonies were recorded only if the subject had been adjudicated for the offense. No subject was included who had been in-program less than one month.

All subjects were seen by two of the authors (an interviewer and an observer) in a structured interview format. The interview consisted of two parts. the first being the Social Adaptation and Interpersonal Relations sections of the Diagnostic Interview for Borderlines (DIB), ${ }^{9}$ the second being the Schedule for Affective Disorders and Schizophrenia (SADS). ${ }^{22}$ The use of the Social Adaptation and Interpersonal Relations section of the DIB allowed the interviewer to obtain specific information about the subject's school performance and relationships with others. The SADS permitted the interviewer to inquire about specific psychiatric symptomatology, both current and past. Following the completion of the intervicw. DSM-III diagnoses were assigned based on the consensus of the two examiners. In all cases, one diagnosis was designated as a primary diagnosis, indicating that based on the clinical judgment of the authors, this diagnosis was the major contributor to the pattern of psychiatric symptomatology seen at the time of the evaluation. The remaining three sections of the DIB (impulse. affect, psychosis) which had not been completed during the interview were then scored, based on information generated during the interview. DIB scoring generated a DIB total score, 5 scaled section scores from the social adaptation. etc. sections and 29 statement scores.

\section{RESULTS}

Eighty-four subjects (48 males and 36 females) were chosen for evaluation using the criteria described above. Of these, 71 (40 male and 31 female) were actually evaluated. Two subjects refused to participate and the remainder were either truant or discharged prior to evaluation. The average age of the subjects chosen for study was 16.3 with a range of 14 to 18 . Thirty-nine subjects were white, 26 black, 6 
Hispanic or other. As a group, subjects were of low socioeconomic status as measured by the Hollingshead-Redlich two-factor scale.

The group studied was composed of adolescents whose legally defined level of delinquency was similar, and involved repetitive and serious felonious acts. Fiftyeight $(87 \%)$ of subjects had committed one or more violent or three or more nonviolent felonies.

The primary diagnosis of the 71 subjects studied is presented in Table 1 . Twentysix $(37 \%)$ of subjects were assigned the DSM-III diagnosis of borderline personality disorder. Eleven (15\%) were diagnosed as having major affective disorders and 3 (4\%) received a primary diagnosis of schizophrenia. For purposes of comparison, subjects were placed in one of four groups based on their primary diagnosis: the borderline group, the major affective disorder group, the schizophrenia group, and the other psychiatric diagnosis group. The other psychiatric diagnosis group included subjects with conduct, personality, minor mood disorders, substance abuse, and mild mental retardation as primary diagnoses.

In Fig. 1 the distribution of total DIB scores is presented for the four diagnostic groups. The mean total DIB score for subjects in the DSM-III borderline group was 7.9, the major affective group 7.5, the schizophrenia group 5.3, and the other psychiatric group 4.9. Subjects in the borderline group scored significantly higher than subjects in the schizophrenia group $(P .01$, Fisher exact test) and the other psychiatric diagnosis group ( $P .01$, Fisher exact test) but were not significantly different than subjects in the major affective group.

Following the convention of Gunderson, a DIB total score of 7 was used as a cutoff score for the diagnosis of borderline personality disorder. Using this cutoff, $73 \%$ of subjects in the DSM-III borderline group were corrently categorized as borderline and $27 \%$ were inappropriately excluded from the diagnosis (false negatives) by the DIB total score. Again, using 7 as a cutoff score, $20 \%$ of subjects were incorrectly assigned a borderline diagnosis (false positives) by the DIB. Of these 14 false-positive subjects, nine were from the major affective group and five were from the other diagnosis group. Using 8 as a cutoff score for the diagnosis of borderline personality, $62 \%$ of the DSM-III borderline group were correctly categorized by the DIB, and the rate of false-positives fell to $10 \%$. As the data indicates, the majority of false-positive results are contributed by subjects from

Table 1. DSM-III Primary Diagnoses

\begin{tabular}{|c|c|c|c|}
\hline & $N$ & Male & Female \\
\hline \multicolumn{4}{|l|}{ Axis I } \\
\hline Schizophrenia & 3 & 3 & 0 \\
\hline Affective disorder & 11 & 4 & 7 \\
\hline Dysthymic disorder & 2 & 2 & 0 \\
\hline Mental retardation & 3 & 2 & 1 \\
\hline Substance abuse & 7 & 5 & 2 \\
\hline Conduct disorder & 6 & 4 & 2 \\
\hline \multicolumn{4}{|l|}{ Axis II } \\
\hline Borderline personality & 26 & 15 & 11 \\
\hline Paranoid/schizoid/schizotypal & 4 & 3 & 1 \\
\hline $\begin{array}{l}\text { Mixed atypical or other personality dis- } \\
\text { order }\end{array}$ & 9 & 2 & 7 \\
\hline
\end{tabular}




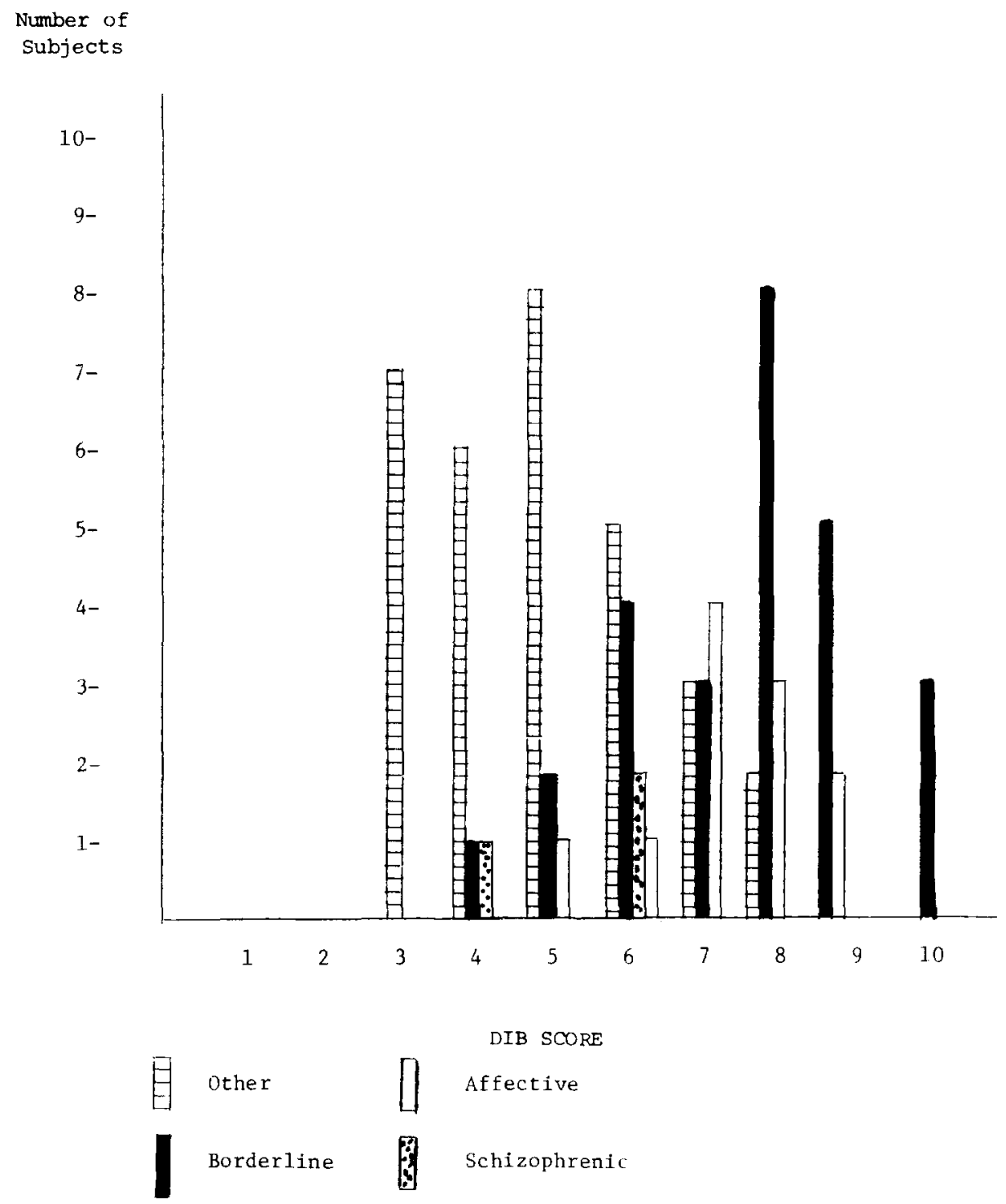

Fig. 1. Distribution of total DIB scores.

the major affective disorder group. When these subjects are dropped from the analysis the percentage of false-positives falls to $7 \%$ using a cutoff score of 7 , and $3 \%$ using a cutoff score of 8 .

The mean scaled scores of the five sections of the DIB are presented in Table 2. Only one section score, psychosis, clearly distinguished the borderline group from the major affective group. There was a trend towards a significant difference in the affect section, where the major affective group tended to score higher.

DIB section scores were more successful in differentiating the other diagnosis 
Table 2. DIB Subscale Scores by Diagnostic Category

\begin{tabular}{lccrc}
\hline & $\mathrm{B}$ & $\mathrm{A}$ & $\mathrm{S}$ & $\mathrm{O}$ \\
\hline Social adaptation & 1.9 & 1.9 & 1.3 & 1.9 \\
Impulse & 1.8 & 1.7 & .7 & $1.0^{\mathrm{a}}$ \\
Affect & 1.4 & $1.7^{\mathrm{b}}$ & 1.0 & $.7^{\mathrm{c}}$ \\
Psychosis & 1.1 & $.5^{\mathrm{d}}$ & 1.2 & $.2^{\mathrm{e}}$ \\
Interpersonal relations & 1.7 & 1.5 & 1.3 & $1.2^{\mathrm{b}}$ \\
\hline
\end{tabular}

a.d $P .05$, ANOVA, DF $=2$

(trend) $P .10$, ANOVA, DF $=2$

$c, P .001$, ANOVA, DF $=2$

i $P .01$, ANOVA, DF $=2$

group from the borderline group. The other diagnosis group received significantly lower scores for four of the DIB sections, impulse, affect, psychosis and interpersonal relations. Like the major affective group, the other diagnosis group was not differentiated from the borderline group by the social adaptation scale score. These three groups of subjects all demonstrated a pattern of poor school performance combined with superficial social adjustment.

The small number of schizophrenic subjects makes meaningful comparison of this group with the borderline group difficult. However, the social adaptation and impulse section scores did significantly differentiate these two groups, with the schizophrenic group scoring lower on both sections. Overall, as was the case with the DIB total scores, the DIB section scores were successful in differentiating the borderline group from the other diagnosis and schizophrenic groups, but not from the major affective group.

In Table 3 the 29 individual statement scores are presented for the four diagnostic groups. Because of their small numbers, schizophrenic subjects were excluded from the analysis and are presented for descriptive comparison. There appear to be substantial differences between the schizophrenic and borderline groups in many statement scores from all five DIB sections.

As would be expected from the DIB total and section scores, none of the statement scores in the social adaptation section differentiated the major affective group from the borderline group. In the impulse section, the wrist slashing statement significantly distinguished the major affective and borderline groups, with the borderline groups scoring significantly higher on this statement. Two statements in the affect section, the depression and chronic dysphoria statements differentiated the major affective and borderline groups. The major affective group scored significantly higher on both statements. Two statements, brief paranoid experiences and regression were also significant in differentiating these two groups. None of the statements in the interpersonal relations section were found to differentiate the major affective and borderline groups.

As was true with the major affective group, none of the statement scores in the social adaptation section differentiated the other diagnosis and borderline groups. Two statement scores in the impulse section, wrist slashing and manipulative suicide were significantly higher in the borderline group. In the psychosis section four statements, derealization, brief paranoid experiences, psychotic experiences with drugs and regression, significantly differentiated the other diagnosis and borderline groups. Finally, in the interpersonal relation section, three statement scores were 
Table 3. DIB Statement Scores by Statement

\begin{tabular}{|c|c|c|c|c|c|}
\hline & & $\mathrm{B}$ & $A$ & S & 0 \\
\hline \multicolumn{6}{|c|}{ Social adaptation } \\
\hline S1. & Stability in work or school & 1.6 & 1.6 & 1.5 & 1.8 \\
\hline S2. & Special achievement effectiveness & 1.1 & 1.0 & .20 & .9 \\
\hline s3. & Active social life & 1.2 & 1.3 & 1.0 & 1.3 \\
\hline S4. & Appropriate with peers & 1.6 & 1.8 & 1.0 & 1.7 \\
\hline \multicolumn{6}{|c|}{ Impulse action patterns } \\
\hline S5. & Slashed wrist, self-mutilation & 1.1 & $.5^{*}$ & 0 & $.3^{* \star}$ \\
\hline S6. & Manipulative suicide threat or effort & 2.2 & 2.2 & 0 & $.7 *$ \\
\hline S7. & Drug abuse & 1.5 & 1.4 & .5 & 1.3 \\
\hline S8. & Promiscuity, homosexuality, sexual deviance & .6 & .5 & 0 & 5 \\
\hline S9. & Runaway, assaults, antisocial acts & 2.0 & 2.0 & 1.3 & 1.9 \\
\hline \multicolumn{6}{|l|}{ Affects } \\
\hline S10. & Appears depressed, recent or chronic symp- & & & & \\
\hline S11. & $\begin{array}{l}\text { toms } \\
\text { Angry, hot-tempered, sarcastic }\end{array}$ & $\begin{array}{r}.9 \\
1.8\end{array}$ & $\begin{array}{l}1.8^{*} \\
1.6\end{array}$ & .2 & $\stackrel{.8}{1.0^{*}}$ \\
\hline S12. & Demanding, entitled & 1.4 & 1.0 & 1.3 & $.7^{* *}$ \\
\hline & Chronic dysphoria, anhedonia, emptiness, & & & & \\
\hline S13. & Ioneliness & .7 & $1.4^{*}$ & .8 & .6 \\
\hline S14. & Appears flat, has been elated & .1 & .5 & .2 & .2 \\
\hline \multicolumn{6}{|c|}{ Psychosis } \\
\hline S15. & Experiences derealization & .7 & .7 & 2.0 & $1^{*}$ \\
\hline S16. & Experiences depersonalization & .4 & .5 & .7 & .05 \\
\hline \multirow[t]{2}{*}{ S17. } & Brief psychotic, depressed experience, sus- & & & & \\
\hline & tained hopelessness-worthlessness & 2 & .1 & .5 & .05 \\
\hline S18. & $\begin{array}{l}\text { Drug-free, brief paranoid experiences } \\
\text { Psychotic, experiences with use of marijuana }\end{array}$ & 6 & $.1^{*}$ & 1.3 & $.2^{*}$ \\
\hline S19. & or alcohol & .8 & .4 & .7 & $1^{*}$ \\
\hline \multirow[b]{2}{*}{ S21. } & Drug-free hallucinations or delusions & .3 & .1 & 3 & .05 \\
\hline & $\begin{array}{l}\text { Manic episodes, persistant, widespread delu- } \\
\text { sions or hallucinations }\end{array}$ & 1 & .4 & 7 & 1 \\
\hline \multirow[t]{2}{*}{$\mathrm{S} 2$} & Transient psychosis in psychotherapy, regres- & & & & \\
\hline & & .3 & $.0^{\star}$ & .2 & $0^{*}$ \\
\hline \multicolumn{6}{|c|}{ Interpersonal relations } \\
\hline $\mathrm{s} 23$. & Avoids being alone & 1.0 & .8 & .2 & 1.0 \\
\hline \multirow[t]{2}{*}{ S24. } & Socially isolated, "Ioner" & .5 & .2 & .8 & 3 \\
\hline & Seeks care of others, conflict over giving or & & & & \\
\hline S25. & receiving care & 1.1 & 1.5 & .5 & 1.0 \\
\hline S26. & Intense, unstable relationships & 1.6 & 1.4 & 1.0 & $.9 * *$ \\
\hline S27. & Devaluation, manipulation, hostility & 1.6 & 1.4 & .8 & $.8 * *$ \\
\hline S28. & Dependency, masochism & 1.1 & .9 & 1.5 & .9 \\
\hline $\mathrm{S} 29$. & Staff splitting, countertransference problems & 1.2 & .8 & 1.0 & $6^{*}$ \\
\hline
\end{tabular}

${ }^{\star} P<.05$, ANOVA

${ }^{\star *} P=.00001$, ANOVA

found to distinguish the other diagnosis and borderline groups. Those statements were intense, unstable interpersonal relationships, devaluation and staff splitting.

In summary, the picture of the seriously delinquent borderline adolescent that emerges from analysis of the DIB is that of an adolescent who is superficially socially appropriate, though unable to produce any sustained achievement in work or school, is affectively labile, self-mutilative, prone to brief periods of paranoid ideation and likely to be involved in relationships where dependency needs are great, but denied and where hostility and instability are prominent. Despite the fact that many nonborderline adolescents share diagnostic features with borderline subjects, borderline delinquent adolescents are readily distinguishable from other diagnostic entities, excepting active major depressive disorder. 


\section{DISCUSSION}

Our study, as outlined previously, was designed to create pilot data and generate hypotheses about borderline personality in adolescence. The data demonstrate that the borderline diagnosis can be made in adolescent subjects using structured interview techniques and DSM-III diagnostic criteria which have been developed for adult populations. Our study also strongly supports previous psychodynamically oriented studies which have suggested that borderline disorders make a substantial contribution to the psychopathology seen in delinquent adolescents.

One aim of the current study was to determine the extent to which the DIB and DSM-III borderline critiera converge in their identification of subjects as borderline. In this aim our study was similar to that of Kroll et al. ${ }^{8}$ who investigated psychiatrically hospitalized adults. They found $80 \%$ of subjects with a DMS-III diagnosis of borderline were similarly classified using the DIB, a figure comparable to the $73 \%$ of DSM-III borderlines appropriately classified by the DIB in our study. In the adult study only $23 \%$ of the subjects "inappropriately" categorized as borderline by the DIB had DSM-III diagnoses of major affective disorder, while in our adolescent study fully $65 \%$ of the "inappropriately" categorized subjects had primary diagnoses of major affective disorder. This comparison indicates that greater problems exist in adolescent subjects in differentiating borderline personality disorder from major affective disorder.

The major affective group in the current study is most similar to the depressed group in the study of Soloff. ${ }^{28}$ Both groups had major affective disorders and were diagnosed using very similar methodologies. Five DIB items distinguished the adolescent borderline group from the major affective group, while in Soloff's sixteen DIB study items distinguished adult borderline and depressed subjects. Four of the five items which distinguished the adolescent major affective group, including depressed affect, self-mutilation, brief paranoia and regression also differentiated adult subjects with borderline personality and major affective disorder. The majority of items which distinguished adult but not adolescent affective disorders from borderlines came from the Impulse and Interpersonal Relations sections. Because behaviors which are reted as part of a pattern of impulsivity by the DIB are common to delinquency, it is not surprising that the Impulse items, excepting selfmutilation and suicide, did not distinguish the borderline and major affective groups. Examination of the Interpersonal Relations items suggests that delinquent adolescents with major affective disorders have difficultes in relatedness which make it difficult to distinguish them from borderline delinquents. Further research is needed to determine if major affective disorders have a similar impact on nondelinquent adolescents, as has been suggested by Stone. ${ }^{23}$

Adult studies using the DIB do not provide a ready comparison group for the other diagnosis group of the current study. Detailed results of evaluation (including DIB statement scores) of subjects with personality disorders other than borderline, substance abuse, etc. is not currently available in the literature. The other diagnosis group is most similar to the "neurotically" depressed group used by Gunderson as a control. ${ }^{5}$ The diagnostic criteria used to select subjects for the "neurotically" depressed group are not spelled out, and this group appears intended to provide a less disturbed, more highly functioning group of subjects with which to compare 
borderline subjects. In this respect, the other diagnosis group and the "neurotically" depressed group are similar.

In comparing these two groups, 7 of the 11 items which distinguished Gunderson's "neurotically" depressed group from adult borderlines also distinguished the other diagnosis group from the adolescent borderlines. These items included the self-mutilation and suicide items from the Impulse Section, the brief paranoia and regression items from the Psychosis section, and three items, unstable relationships, devaluation and splitting items from the Interpersonal Relations section. In our study subjects at "the upper border" in terms of severity of psychopathology were readily distinguished from borderline delinquents, and in a manner consistent with the way in which the DIB differentiated adult borderlines from adults with neurotic depression.

Further investigation of borderline personality in adolescence will require improvements in the methodology employed in this study (independent raters), inclusion of diverse subject populations (psychiatrically hospitalized adolescents, less severely delinquent adolescents), family studies and a search for biological markers (dexamethasone suppression)' which have proven useful in the characterization of adult subjects.

\section{SUMMARY}

Borderline personality disorder makes a substantial contribution to the psychopathology seen in delinquent adolescents. Borderline pathology can be identified reliably in this population using instruments and diagnostic criteria developed for making the borderline diagnosis in adults. The main difficulty in making the diagnosis of borderline personality in delinquent adolescents and perhaps in adolescent populations in general is the differentiation of borderline personality from the major affective disorders.

\section{REFERENCES}

1. Carroll BJ, Greden JF, Feinberg M, et al.: Evaluation of depression in borderline patients. In Stone M. (ed.), Psych Clin of N. Amer, vol. 4, 1:47-58, 1981

2. Chiles $J$, Miller $M$, Cox $G$ : Depression in an adolescent delinquent population. Arch Gen Psychiatry, 37:1179-1184, 1980

3. Grinker RR, Werble B, Dyre RC: The Borderline Syndrome. New York, Basic Books, 1968

4. Gunderson JG, Kobb KE: Discriminating features of borderline patients. Am J Psych 132:1-10, 1975

5. Gunderson JG: Characteristics of borderlines. In Martocollis P (ed.): Borderline Personality Disorders. New York, International Universities Press, 1977

6. Gunderson JG, Singer MT: Defining borderline patients: An overview. Am J Psych 132:1-10, 1975

7. Kashani J, Manning G, McKnew D, et al: Depression among incarcerated delinquents. Psych Res 3:185-191, 1980

8. Kroll J, Sines L, Martin K, Lari S, et al: Borderline personality disorder. Arch Gen Psych 38:1021-1026, 1981

9. Kolb J, Gunderson J: Diagnosing borderline patients with a structured interview. Arch Gen Psych 37:37-41, 1980

10. Lewis DO, Shanok SS: Delinquency and the schizophrenic spectrum of disorders. J Am Acad Child Psych 17:263-276, 1978 
11. Lewis DO, Balla DA: Delinquency and Psychopathology. New York, Grune and Stratton, 1976

12. Masterson J, Costello J: From Borderline Adolescent to Functioning Adult: The Test of Time. New York, Bruner-Mazel, 1980

13. Masterson J: The borderline adolescent. Adoles Psychiatry, 2:240-268, 1973

14. Masterson J: Treatment of the Borderline Adolescent: A Developmental Approach. New York, John Wiley \& Sons, 1972

15. Offer D, Marohn R, Ostrow E: The Psychological World of the Juvenile Delinquent. New York, Basic Books, 1979

16. Perry JC, Klerman GL: The borderline patient. Arch Gen Psych 35:141-150, 1978

17. Rinsley DB: Dynamic and developmental issues in borderline and related spectrum disorders. In Stone M (ed.): Psych Clin of N. Amer, vol. 4, 1:117-131, 1981

18. Rinsley DB: Diagnosis and treatment of borderline and narcissistic children and adolescents. Bull Menninger Clin 44:147-170, 1980

19. Rinsley DB: Borderline psychopathology: A review of aetiology, dynamics and treatment. Int Rev Psycho-Anal, 5:45-54, 1978

20. Soloff P, Ulrich R: Diagnostic interview for borderlines: A replication study. Arch Gen Psych 38:686-692, 1981

21. Soloff P: Concurrent validation of a diagnostic interview for borderline patients. Am J Psych 138:691-693, 1981

22. Spitzer RL, Endicott J: Schedule for Affective Disorders and Schizophrenia (3rd Ed.). Biometrics Research, New York State Psychiatric Institute, 1977

23. Stone M: Depression in borderline adolescents. Am J Psychother 25:383-399, 1981

24. Taylor-Gibb J: Personality patterns of delinquent females: ethnic and socioculteral variations. J Youth Adolescence 10:2:17-24, 1981 